\title{
Invitación al aprendizaje vitalicio
}

\author{
Invitation to a lifelong learning experience
}

Ana María Wintergerst Lavín*

Vivimos en un mundo en constante movimiento, en el cual, un área de gran dinamismo es la del conocimiento que se incrementa en forma exponencial. Gran parte de lo que se conoce hoy, no se conocía ayer y al mismo tiempo es posible que no sea válido mañana. Se le ha llamado vida media del conocimiento al tiempo que transcurre desde que se obtiene cierta comprensión hasta que la mitad de éste se vuelve obsoleto. También se habla de la vida media de la competencia profesional al tiempo transcurrido desde el final de la preparación profesional de una persona hasta el tiempo en que ésta sea aproximadamente la mitad de competente de lo que era al graduarse aunque en esa primera etapa, en realidad, se es novato y con la experiencia se llega a ser experto.

Hace sólo algunas décadas una persona que terminaba sus estudios universitarios poseía el acervo de conocimientos que utilizaría durante su vida profesional, retornando a la educación formal en forma ocasional. Sin embargo, este modelo está «extinto» porque no se puede esperar que la educación formal aun a nivel de postgrado sea suficiente para toda la vida profesional.

¿Podríamos pensar entonces que nuestro conocimiento tiene una fecha de expiración? No, dado que el conocimiento no evoluciona en forma sistemática y predecible: la velocidad de cambio es distinta en diferentes campos del conocimiento e incluso dentro de un mismo campo.

No sería fácil establecer la vida media del conocimiento en odontología pero es claro que nuestra profesión ha cambiado radicalmente desde que Pierre Fauchard, Padre de la Odontología Moderna, publicara en 1728 el libro de texto «El cirujano dentista o tratado sobre los dientes», aunque algunos principios como la desaprobación de la irreflexiva extracción de molares temporales, siguen vigentes.

Un cirujano dentista a principios del siglo XX no se veía en la necesidad de incorporar tantos avances y cambios desde el término de sus estudios hasta su retiro como los que vivirá uno a principios del siglo XXI.
Un cirujano dentista egresado de las aulas universitarias en la década de los 80 ha presenciado la introducción del uso de resinas fotopolimerizables, medios de barrera para control de infecciones, láseres, fotografía y radiología digital, blanqueamiento, brackets adheribles y autoligables, implantes y mini-implantes por mencionar algunos. Ha presenciado, así mismo, cambios en el enfoque del pensamiento como el de la extensión por prevención al de la odontología mínimamente invasiva.

Las mayores posibilidades de prevenir la enfermedad y mejorar la salud, de proporcionar la mejor atención a los pacientes y de tener éxito y competitividad en el siglo XXI dependerán del ejercicio del aprendizaje como proceso permanente a lo largo de la vida. Los jóvenes habrán de ser proactivos y habrán de asumir la responsabilidad de la dirección y calidad de su propio aprendizaje. Se requiere, por lo tanto, saber aprender como adultos. Quizá sea más trascendente adquirir la capacidad de poder aprender mañana que el adquirir hoy conocimientos, tal vez perecederos. La adquisición de la competencia de ser estudiantes vitalicios y de las habilidades para practicar la odontología basada en la evidencia debe ser desarrollada en la universidad. Debe ser integrada como parte del currículo, por lo tanto, la preparación para aprender y re-aprender, para ser eficientes en el manejo de la sobrecarga de información, para identificar qué, dónde, y cuándo aprender, aún más, a ser selectivos, a ser clientes exigentes del conocimiento sabiéndolo evaluar. En otras palabras, a forjar un pensamiento crítico.

\footnotetext{
* Profesora y tutora del Programa de Maestría y Doctorado en Ciencias Médicas, Odontológicas y de la Salud, Facultad de Odontología, UNAM.
}

Este artículo puede ser consultado en versión completa en http://www.medigraphic.com/facultadodontologiaunam 
El pensamiento crítico implica la reflexión autónoma; es un atributo cognitivo y del comportamiento. Es la capacidad de entender, apreciar y valorar el significado de hechos, acciones abiertas y encubiertas e intenciones, incluyendo la capacidad de dudar, de juzgar, de lograr conclusiones para actuar con un propósito y un comportamiento no sólo independiente sino congruente de acuerdo con ese propósito. Así entendida, la reflexión incluye el respeto a los enfoques científicos y profesionales dispares.

En Odontología, como en otras ciencias, es responsabilidad del investigador difundir sus resultados. El impactante desarrollo tecnológico permite que ese conocimiento sea global a pesar de periodos de demora o de barreras hacia su aplicación clínica. Es imposible, además, concebir actualmente un cuerpo de conocimiento científico-profesional como recurso estable durante toda la vida. El mantenerse adecuadamente actualizado es un reto. Imaginemos a un paciente que al acudir al odontólogo ya realizó una búsqueda no académica en Internet y solicita se le realice específicamente «X» procedimiento. El odontólogo habrá de poseer bases sólidas para decidir, dado el diagnóstico y circunstancias particulares, si tal tratamiento es el más indicado e idóneo para ese paciente, así como la fundamentación para persuadirlo de su inaplicabilidad en caso de que la terapéutica que él solicita no sea la adecuada.

El manejo de la información es complejo puesto que no es un objeto que pueda ser almacenado, poseído o transportado como lo es un documento. Los conocimientos fiables no pueden provenir de la intuición, la revelación, el rumor o la imitación. Deben ser el producto de alguna forma de procedimiento sistemático. Los conocimientos adquiridos en la universidad servirán de base pero deberán adaptarse a nuevos factores y nuevos problemas. Aprendamos a evaluar los cambios, aceptarlos si es prudente o adaptarlos. Aprendamos también a manejar cambios en los paradigmas, a distinguir qué principios permanecen y cómo integrar el o los nuevos datos o desarrollos con las habilidades y conocimientos existentes.

Nunca perdamos el entusiasmo por aprender. El aprendizaje de por vida y el reconocimiento de la naturaleza evolutiva del conocimiento es importante pero no más que el juicio clínico, la experiencia clínica la cual se incrementa con el tiempo, el sentido común y la ética profesional.

Dirección para correspondencia:

Ana María Wintergerst Lavín

E-mail: anawintergerst@yahoo.com 